\section{Estudo \\ cobebate}

em Cestão

Planejamento
Revista Estudo \& Debate, Lajeado, v. 27, n. 4, 2020. ISSN 1983-036X

DOI: http://dx.doi.org/10.22410/issn.1983-036X.v27i4a2020.2587

\title{
ECONOMIA E RELIGIOSIDADE: UMA REVISÁO DO ESTADO DA ARTE (2000 - 2019)
}

\author{
Max Nunes Murtinho ${ }^{1}$
}

\begin{abstract}
Resumo: O objetivo deste estudo é analisar o estado da arte da pesquisa sobre religiosidade e economia, revisando e analisando os artigos mais citados publicados entre 2000 e 2019. Para tanto, utilizou-se no artigo, os métodos da pesquisa bibliométrica e bibliográfica. Os resultados mostram que o interesse pela capacidade da religião impactar o crescimento econômico e o desenvolvimento econômico continua elevado. Há sempre muito cuidado nas interpretaçóes de resultados empíricos, na qual raramente algum autor vai além do conceito de associação ou correlação em suas consideraçóes. O debate sobre a validade da tese weberiana não ficou de fora da pesquisa de alto impacto. Parece se confirmar a capacidade da ética protestante em influenciar tanto o crescimento econômico, quanto atitudes que favorecem a produtividade, como a educação, por exemplo. Além disso, a pesquisa recente sobre religiosidade apresenta forte caráter microanalítica e baixa solidez teórica, quase não havendo esforços na construção de modelos teóricos.
\end{abstract}

Palavras-chave: Religiosidade, Crescimento Econômico, Desenvolvimento Econômico, Eficiência Econômica, Estado da Arte.

\section{ECONOMY AND RELIGIOSITY: A REVIEW OF THE STATE OF ART (2000 - 2019)}

\begin{abstract}
The aim of this study is to analyze the state of the art of research on religiosity and economics, reviewing and analyzing the most cited articles published between 2000 and 2019. For this purpose, the methods of bibliometric and bibliographic research were used in the article. The results show that interest in the ability of religion to impact economic growth and economic development remains high. There is always great care in the interpretation of empirical results, in which rarely does any author go beyond the concept of association or correlation in his considerations. The debate on the validity of the Weberian thesis was not left out of high-impact research. It seems to confirm the capacity of Protestant ethics to influence both economic growth and attitudes that favor productivity, such as education, for example. In addition, recent research on religiosity has a strong microanalytical character and low theoretical strength, with almost no efforts in the construction of theoretical models.
\end{abstract}

Keywords: Religiosity, Economic Growth, Economic Development, Economic Efficiency, State of the Art.

1 Doutor em Administração pela Universidade Nove de Julho - Uninove; docente em regime de dedicação exclusiva na Faculdade de Economia da Universidade Federal de Mato Grosso 


\section{Introdução}

A religiosidade recentemente tem atraído algum interesse da pesquisa econômica (GADELHA; ARANTES JUNIOR, 2017). E, de fato, grande parte dessas pesquisas têm evidenciado certa associação entre a religiaao e a atividade econômica (MCCLEARY; BARRO, 2006a; BLUM; DUBLEY, 2001). Uma das razóes é que as religióes têm se oferecido como uma alternativa ética para os seus fiéis (MAGILL, 1992) influenciando na sua tomada de decisão. Surpreende que algo tâo importante na vida das pessoas, não seja mais intensamente pesquisada, pois, a religiáo determina doutrinas e princípios que impacta no comportamento de seus membros mais fiéis, moldando interaçóes econômicas, políticas e sociais (NORTH, 1991).

A primeira pesquisa sobre a ligação entre religião e economia foi a de Weber (1904). No livro "Ética Protestante e o Espírito do Capitalismo" Weber destaca que a ética protestante diferia radicalmente da ética católica. Enquanto os católicos ensinam a caridade, boas ações e certo ascetismo em relação aos bens materiais, os protestantes promovem o trabalho e sucesso material como um requisito da escolha dos fiéis. Com isso, países cuja população fosse predominantemente protestante, tenderiam a serem mais competitivos e produtivos, por conseguinte, possuindo maior prosperidade material (WEBER, 1904).

Diversas são as pesquisas empíricas que tentam confirmar ou refutar a tese weberiana. E um dos desafios que a pesquisa sobre religiosidade e economia tem enfrentado é a dificuldade em se quantificar a variável religiosidade/religiaao (GUISO; SAPIENZA; ZINGALES, 2003). Apesar disso, nessas pesquisas, se têm evidenciado associaçóes positivas entre as variáveis. Becker e Woessman (2009), por exemplo, ao estudarem o desenvolvimento econômico da Prússia, perceberam que foi a educação protestante, e não a ética protestante, a razão do sucesso econômico de naçóes protestantes. Isso ocorreu, muito provavelmente, pela necessidade maior da leitura da Bíblia dos protestantes em relação aos católicos. Também se evidenciou que as religiôes podem afetar diretamente a produtividade conforme se modificam as interações econômicas e sociais entre religiosos e não religiosos (GADELHA; ARANTES JUNIOR, 2017).

No que diz respeito à pesquisa empírica, os primeiros estudos remontam o período pós Segunda Guerra Mundial. No entanto, ainda consideravam a religião apenas como um elemento da cultura, sendo esta a variável em análise (SOLOW, 1956; SCHULTZ, 1961; BECKER, 1962). Vale ressaltar que há uma linha específica do estudo da religião na economia denominada Economia da Religião, que analisa o comportamento religioso, a partir da perspectiva da Teoria da Escolha Racional (NASCIMENTO; ROCCO, 2018). A primeira pesquisa da Economia da Religião foi a de Azzi e Ehrenberg (1975).

Além da discussão em torno da tese weberiana, que circunda o cristianismo, há também estudos sobre outras religióes na atividade econômica. Campante e YanagizawaDrott (2015), por exemplo, estimaram os efeitos do jejum muçulmano durante o Ramadã. Concluíram que se o jejum diário fosse maior que 12 horas (tempo padrão), o crescimento econômico tenderia a diminuir, em contrapartida a satisfação e bem-estar tenderiam a aumentar. 
Em vista da dificuldade de se medir o impacto da religião na Economia, por conta de sua complexidade e também pelo baixo reconhecimento de sua importância no estudo da economia, pretende-se analisar o estado da arte da pesquisa sobre religiosidade e economia, revisando e analisando os artigos mais citados publicados entre 2000 e 2019 . Para tanto, utilizou-se os métodos da pesquisa bibliométrica e bibliográfica. Este trabalho visa promover um maior desenvolvimento da pesquisa sobre religiosidade e economia, considerando certo grau de rudimentariedade na pesquisa atual, haja vista que os estudos sáo esparsos, microanalíticos e carecem de uma teorização mais sólida (GUISO; SAPIENZA; ZINGALES, 2003).

\section{Revisão da Literatura}

A influência da religião na economia é um tema assíduo na história (AYDEMIR; EGILMEZ, 2010). Pesquisas empíricas têm demonstrado que a religião influencia fortemente nas atitudes e comportamentos do indivíduo. Possivelmente, isso se deve a autoidentidade religiosa, que é formada pela internalização do papel do indivíduo frente as expectativas fornecidas pela religiáo escolhida (WEAVER; AGLE, 2002).

Uma religiáo é uma crença em uma divindade, que pode ser acompanhada de compromisso em seguir os princípios nela estabelecidos (MCDANIEL; BURNETT, 1990; JOHNSON; JANG; LARSON; LI, 2001). Allport e Ross (1967) definem como a medida em que uma pessoa vive suas crenças religiosas. A literatura filosófica define religião como o conjunto de conhecimentos, açōes e estruturas com as quais o ser humano expressa reconhecimento, dependência e veneração ao sagrado (MONDIN, 1980). Bjarnason (2007) vislumbra na religião três dimensôes: afiliação religiosa, atividade religiosa e crença. Nos estudos aplicados muito se utiliza as dimensôes de religiosidade de Allport (1950): intrínseca e extrínseca. A intrínseca diz respeito à satisfação religiosa em si e a extrínseca tem a ver com a valorizaçáo dos fatores externos que podem beneficiar o indivíduo ao externalizar sua religiosidade.

O ponto de partida da pesquisa sobre a religião na economia, remonta as contribuiçóes de Weber e Marx sobre o tema (STEUART, 1998). Embora ambos correlacionam as variáveis, Marx entende que o modo de produção do sistema capitalista é que molda a religião, e não o contrário (MARX, 1843). Weber, por sua vez, ainda que focando sua análise no cristianismo, defende que a ética protestante foi a mola propulsora do ímpeto produtivo capitalista (WEBER, 1904). Além destes, Adam Smith também atribui à religiấo, a capacidade de influenciar no modo de vida, e por extensão, as decisóes econômicas do indivíduo (SMITH, 2007).

Sobre a controvérsia cristá, que dividiu católicos e protestantes, se iniciou quando a Igreja Católica começou a vender indulgências, vindo a acender uma espécie de competição religiosa (EKELUND JUNIOR; HÉBERT; TOLLISON, 2002). A Reforma Protestante só veio a crescer porque grande parte da populaçáo demonstrava insatisfação teológica, política e socioeconômica com a Igreja Católica. Os mais abastados tinham larga vantagem na apropriação das "bençãos" oferecidas, já que, a indulgência era uma oportunidade de se protegerem do purgatório e do juízo eterno (LUTERO, 2004; MICHELLON, 2006). 
A tese weberiana sobre a influência do protestantismo no sistema capitalista, ao menos na pesquisa econômica, parece ter mais força que a posição marxista. Landes (1998), por exemplo, pontua que o protestantismo auxiliou na ascensão da Revoluçáo Industrial, não por meio de uma maior liberdade religiosa, mas por sancionar uma ética que conduzia ao sucesso empresarial. Já Laveleye (1985) acrescenta que o protestantismo deu mais ênfase na instrução de seus fiéis que a Igreja Católica. Isso porque o culto protestante tende a fomentar o hábito da leitura, por conta do uso mais frequente da Bíblia, em contrapartida, o culto católico se fundamenta nos sacramentos, na confissão, na missa e no sermão, práticas que não exigem leitura. Os resultados foram um maior nível de alfabetização, inclusive entre as mulheres, e, consequentemente, um maior número de candidatos para a educação avançada (BERNARDELLI; MICHELLON, 2018; MCCLEARY, 2011). Outro diferencial, que permitiu um crescimento maior de igrejas protestantes, foi o trabalho dos missionários, que disseminou a literatura para fins de conversão e proselitismo (WOODBERRY, 2011). O protestantismo oferecia um caminho alternativo e menos dispendioso para a salvação.

Há quem se opóe a tese weberiana. Iannaccone (1998), por exemplo, sustenta que a teoria weberiana é frágil pela "ausência de apoio empírico". Além disso, comprovou-se historicamente que a maioria das instituiçóes capitalistas descritas no trabalho de Weber já existiam antes da Reforma Protestante (SAMUELSSOM, 1993; TAWNEY, 1926). Em uma crítica às análises que confirmam a tese weberiana, Guiso, Sapienza e Zingales (2003) afirmam que, para refutar ou confirmar Weber, seria preciso ir além da análise dos mesmos países protestantes analisados por Weber - algo comum em pesquisas recentes - do contrário, seria o mesmo que replicar empiricamente o seu trabalho.

Outra complexidade que envolve a pesquisa empírica é que, embora diversos pesquisadores julguem que a religiáo afeta a atitude econômica das pessoas (GUISO; SAPIENZA; ZINGALES, 2003), não tem sido tão simples atribuir uma relação causal. Em vista disso, os autores têm sido precavidos na atribuição de causalidade, preferindo os termos correlação e/ou associação. Eisenstadt (1968) e Uppal (1986), por exemplo, ampliaram suas pesquisas para além dos muros da religiosidade cristã, agregando outras religiōes em suas análises. Concluem, por exemplo, que religiôes ascéticas como o hinduísmo e o islamismo, na prática, apresentam comportamentos que, em vez de promover o desinteresse material, promovem o consumo, e, não se opóem tão fortemente a certo nível de ambição material.

Quanto ao início da pesquisa, só após a Segunda Guerra Mundial estudos sistemáticos começaram a surgir (MCCLEARY, 2011). Os primeiros foram os de Solow (1956), Schultz (1961) e Becker (1962). Ao analisar o impacto da cultura na atividade econômica, encontraram associaçáo positiva entre as variáveis. A religiāo, assim como a linguagem, a história, os costumes e as instituiçôes são elementos que definem a cultura de uma sociedade (HUNTINGTON, 1996), e, por isso, a incluíram em suas análises (BERNARDELLI; MICHELLON, 2018). Trabalhos empíricos posteriores confirmaram a relevância de fatores culturais na explicação do crescimento econômico (HUNTINGTON, 1996; LANDES, 1998; INGLEHART; BAKER, 2000), alguns com amostra europeia (GRIER, 1997), confirmando os achados seminais.

Quanto as pesquisas mais recentes, muitas possuem caráter mais microanalítico, focando suas análises em atitudes específicas que promovam ou não o crescimento econômico 
(GUISO; SAPIENZA; ZINGALES, 2003). Pesquisas nessa linha têm evidenciado, por exemplo, que o catolicismo tem associação negativa com o nível de confiança das pessoas (PUTNAM, 1993; LA PORTA et al., 1997; INGLEHART, 1999), e está associado a uma cultura de intolerância (LANDES, 1998). Blum e Dudley (2001) explicam que uma das possíveis razóes do protestantismo promover o crescimento econômico é que a ética protestante eleva a responsabilidade individual, levando ao aumento da confiança e cooperação.

Outras pesquisas têm evidenciado que a religião afeta os salários (CHISWICK, 1983), a frequência escolar (FREEMAN, 1986), a saúde (ELLISON, 1991) e o comportamento criminoso (EVANS et al., 1995). No entanto, como bem lembra Freeman (1986), "crianças boas podem evitar drogas, permanecer na escola e ir à igreja”, com isso, não está claro se a associação entre religião e as variáveis pesquisadas demonstra relação causal (GUISO; SAPIENZA; ZINGALES, 2003).

Apesar de seu valor, a complexidade no estudo das religióes somado a problemas de identificação na pesquisa empírica, dificultam uma construção teórica mais sólida (GUISO; SAPIENZA; ZINGALES, 2003). Além do mais, na ótica da economia, as práticas religiosas podem provocar um trade-off entre o uso de fatores de produção e disponibilidade de tempo, já que o tempo e os recursos produtivos que deveriam estar disponíveis para a produção são desviados para construção de templos, peregrinações, meditações etc. (GADELHA; ARANTES JUNIOR, 2017).

Por fim, vale destacar uma linha de pesquisa específica da economia denominada Economia da Religiáo. Esta linha de pesquisa possui pressupostos rígidos definidos a partir do conceito da Escolha Racional. Diferente da ideia de que a demanda religiosa se altera conforme alteraçóes das preferências do indivíduo, a Teoria da Escolha Racional sustenta que as mudanças religiosas são apenas um resultado das mudanças na oferta religiosa. Isso significa que, em certa medida, o governo e a competição religiosa dos produtores de religião do mercado estariam aptos para influenciarem na demanda religiosa (OLIVEIRA; CORTES; BALBINOTTO NETO, 2011). Como esta pesquisa pretende analisar o interesse entre religiosidade e economia na pesquisa internacional de alto impacto, sem a restriçấo de pressupostos, optou-se por não utilizar a Economia da Religião e a Teoria da Escolha Racional como parâmetro na busca de dados.

\section{Metodologia}

Este artigo é de natureza exploratória tendo como procedimento metodológico a pesquisa bibliométrica e bibliográfica. O levantamento foi realizado por meio da ferramenta de busca Google Scholar (https://scholar.google.com.br/). O recorte temporal é de 2000 a 2019 visando contemplar toda a extensáo do presente século. Os descritores utilizados para o levantamento dos artigos foram: economy; economic; religiosity; religion; religious. O critério de relevância dos artigos foi a quantidade de citaçóes. Se reconhece que a quantidade de citaçóes descritas na ferramenta de busca Google Scholar pode não ser exata, mas também não interfere no ranqueamento dos trabalhos. No levantamento de dados, optou-se por configurar a busca de artigos amarrando os descritores apenas ao título do artigo. Isso 
garantiria uma triagem mais sólida de artigos que realmente contribuísse para o estudo sobre religiosidade e economia.

$\mathrm{Na}$ pesquisa do estado da arte, tem-se utilizado a ferramenta de busca do Google para o levantamento de artigos científicos, haja vista a quantidade maior de artigos encontrados em relação às bases de dados como SCOPUS ou Web of Science. Entretanto, há limitações. A métrica apresentada pelo Google Scholar é mais simples e requer maior esforço operacional do pesquisador para levantar uma estatística mais detalhada. Além disso, livros e artigos de congressos também são levantados pela busca, o que amplia o trabalho do pesquisador que pretenda avaliar o estado da arte de uma pesquisa utilizando apenas artigos de periódicos científicos.

Optou-se neste artigo, avaliar a pesquisa sobre religiosidade e economia considerando todos os tipos de documentos [artigos de periódicos, artigos de eventos, livros etc.], desde que estejam entre os mais citados. Para efeitos de praticidade, em vez do levantamento manual, utilizou-se o software Publish or Perish. No procedimento, se levantou um total de 2269 documentos. No levantamento, identificou-se o percentual de artigo por combinação de descritores (Quadro 1), em seguida buscou-se tendências de pico e vale na publicação anual (Quadro 2), a partir daí centrou-se a análise apenas nos 50 artigos mais citados, visando uma análise mais profunda de seus interesses, a amostra por países, amostra por religião e contribuiçóes mais relevantes. O foco nos 50 artigos mais citados - na qual foi realizada leitura completa do artigo - conferiu maior praticidade na identificação de tendências, preocupaçóes mais salientes e lacunas da pesquisa. Disso resultou a discussão de tendências e sugestóes de pesquisas futuras.

\section{Resultados e Discussáo}

Dos 2269 documentos levantados, 52,6\% não possuíam ainda nenhuma citação, $36,6 \%$ entre 1 e 10 citações, 7,9\% entre 11 e 50 citaçôes, 1,6\% entre 51 e 100 citaçôes e apenas $1,3 \%$ dos documentos apresentaram mais de 100 citaçóes.

Sobre o levantamento de artigos, seis foram as combinações. A combinação de maior percentual foi religious e economic com 38,9\%. A combinação religion e economic vem em seguida com $24 \%$ dos artigos. A combinação com menor número de artigos foi religiosity e economy, representando apenas $0,6 \%$, não tendo sequer um artigo entre os 50 mais citados. É perceptível que o termo economic é mais utilizado nos títulos dos artigos que economy. O motivo disso, provavelmente, é a maior flexibilidade do termo economic - no português, econômico - que permite termos compostos como: crescimento econômico, desenvolvimento econômico, atividade econômica etc. Já o termo economy - no português, economia - é mais restrito para termos compostos, sendo mais utilizado como sinônimo de ciência econômica ou quando se refere a economia de um país ou região. Além do mais, observou-se entre os artigos de alto impacto, o baixo uso do termo "Economia da Religião". Isso parece indicar que os pesquisadores não desejam restringir suas análises ao pressuposto microeconômico da Escolha Racional.

No Quadro 1, apresenta-se os 50 artigos de maior relevância [em citaçôes] no estudo sobre religiosidade e economia entre 2000 e 2019 . Nota-se que amostras intercontinentais 
equivalem a 40\% do total. Em segundo vem as amostras europeias com 20\% [amostras de Holanda, Reino Unido, Espanha, Grécia, Irlanda, Hungria], em terceiro a Ásia com 14\% [amostras do Sul da Ásia, Ilhas Moluscas, Laos e Vietnã, Índia e China], em quarto a América do Norte com 8\% [todas elas dos Estados Unidos], em quinto a África com 6\% [amostras de Nigéria e Bangladesh] e, por último, a América Latina representando apenas $2 \%$ das amostras entre os artigos mais relevantes. Os 10\% restantes são trabalhos teóricos.

O ponto negativo fica para a baixa representatividade da África, e, principalmente, da América Latina, na qual se inclui o Brasil. Isso tem potencial de gerar um viés nos resultados já que, tanto a África quanto a América Latina são os continentes onde a religiosidade de sua população tem sido maior e mais intensa (CARVALHO, 1999).

Quadro 1 - Amostras por continentes dos 50 artigos de maior impacto $(2000$ - 2019) quadro corrigido

\begin{tabular}{|c|l|c|c|l|}
\hline Posiçáo & Amostra & $\mathbf{N o}^{\circ}$ Amostras & Percentual & Países \\
\hline $1^{\mathbf{o}}$ & Intercontinental & 20 & $40 \%$ & \\
\hline $2^{\circ}$ & Europa & 10 & $20 \%$ & $\begin{array}{l}\text { Europa (2); Holanda (2); Reino } \\
\text { Unido (2); Espanha (1); Grécia (1); } \\
\text { Irlanda (1); Hungria (1). }\end{array}$ \\
\hline $3^{\circ}$ & Ásia & 7 & $14 \%$ & $\begin{array}{l}\text { Sul da Ásia (1); Ilhas Moluscas (1); } \\
\text { Laos e Vietnã (1); Índia (2); China } \\
(2) .\end{array}$ \\
\hline $4^{\mathrm{o}}$ & $\begin{array}{l}\text { América do } \\
\text { Norte }\end{array}$ & 4 & $8 \%$ & Estados Unidos (4). \\
\hline $5^{\circ}$ & África & 3 & $6 \%$ & Nigéria (2); Bangladesh (1). \\
\hline $6^{\mathrm{o}}$ & América Latina & 1 & $2 \%$ & América Latina (1) \\
\hline & $\begin{array}{l}\text { S/ amostra } \\
\text { (teórico) }\end{array}$ & 5 & $10 \%$ & \\
\hline
\end{tabular}

Fonte: Elaboração do autor (2020).

Em relação às religiôes pesquisadas, entre os 50 artigos de maior impacto (Quadro 4), tem-se $54 \%$ de artigos com amostras sem definição de religião. Esta proporção segue leve correlação com os trabalhos de amostras intercontinentais. Depois, vem o cristianismo (sem distinção entre católicos e protestantes) em segundo lugar com $18 \%$ das amostras, sendo seguido por amostras católicas (12\%), islâmicas (12\%), protestantes $(6 \%)$, hindus (4\%), budistas (2\%) e outros (2\%). A presença da fé cristã nas pesquisas de alto impacto é tão forte que, se somarmos as amostras sem especificação de religiâo (supondo que nessa amostra há cristãos) com a amostra do cristianismo, catolicismo e protestantismo, daria $90 \%$ de todos os artigos. 
Quadro 2 - Amostras de religiōes ou denominaçóes religiosas entre os 50 artigos de maior impacto (2000 - 2019) quadro corrigido

\begin{tabular}{|c|l|c|c|}
\hline Posição & Religiáo ou denominação religiosa & Amostras & Percentual \\
\hline $1^{\mathrm{o}}$ & Religiosidade sem especificar religião & 27 & $54 \%$ \\
\hline $2^{\mathrm{o}}$ & Cristianismo (sem distinguir católicos e protestantes) & 10 & $20 \%$ \\
\hline $3^{\mathrm{o}}$ & Catolicismo & 3 & $6 \%$ \\
\hline $4^{\mathrm{o}}$ & Islamismo & 4 & $8 \%$ \\
\hline $5^{\mathrm{o}}$ & Protestantismo & 1 & $2 \%$ \\
\hline $6^{\mathrm{o}}$ & Hinduísmo & 1 & $2 \%$ \\
\hline $7^{\mathrm{o}}$ & Religióes comparadas & 3 & $6 \%$ \\
\hline $8^{\mathrm{o}}$ & Outro (religióes locais) & 1 & $2 \%$ \\
\hline & Total & 50 & 100 \\
\hline
\end{tabular}

Fonte: Elaboração do autor (2020).

\subsection{Contribuiçáo dos 50 artigos mais citados}

De longe, o maior interesse da pesquisa de alto impacto sobre religiosidade na economia é a capacidade da religiáo em influenciar no crescimento econômico de um país. Blum e Dubley (2001), analisaram a hipótese de Weber sobre a relação positiva entre o crescimento econômico e o protestantismo utilizando escassas amostras europeias da Idade Moderna. Os autores sustentam que não é possível explicar o crescimento de algumas cidades europeias apenas pelo comportamento de indivíduos protestantes. Para eles, o que mais influenciou no crescimento de cidades protestantes foi o acesso direto ao Atlântico, contribuindo para o avanço da tecnologia marítima, o que reduz significativamente o custo do transporte marítimo. Porém, a hipótese de Weber sobre uma tendência maior das redes de informação entre cidades protestantes pode ser mantida. As razóes disso é que, comparado aos católicos, os protestantes eram mais alfabetizados e honrar melhor seus contratos com desconhecidos, promovendo uma qualidade maior na interação entre os atores. Barro e McCleary (2003) também mostram que o crescimento econômico responde positivamente às crenças religiosas, de forma saliente em relação às crenças no céu e inferno, mas negativamente à frequência à igreja. Para os autores, o crescimento depende da extensão da crença em relação ao pertencimento. Também encontraram que, para determinadas crenças, uma maior frequência à igreja significa mais recursos usados pelo setor religioso.

Hirschle (2010) testa três hipóteses que possam explicar uma possível relação

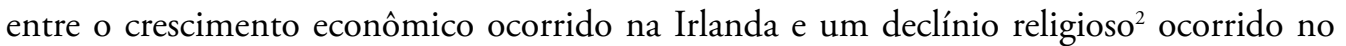
mesmo período. A primeira hipótese é a da Teoria da Secularização, na qual se postula que o crescimento econômico aumenta a segurança existencial, e, que, por sua vez, reduz os valores religiosos e a frequência à igreja. A segunda hipótese é a explicação orientada para o consumo, na qual, o crescimento econômico não necessariamente compete com a

2 Amostra predominantemente católica, por abranger praticamente $80 \%$ de toda a população, mas os autores agregaram na amostra todas as religióes cristãs do país. 
religiáo, mas, seu aumento, resultante desse crescimento, reduz o interesse pela religiáo. Por fim, a terceira hipótese, o problema da alocaçâo de tempo, na qual, mais tempo de lazer e trabalho reduzem o tempo para dedicar à religiáo, sem necessariamente atingir seus valores e crenças. $\mathrm{O}$ autor confirmou empiricamente que o crescimento econômico está significativamente associado ao declínio da prática religiosa, sendo a faixa etária entre 18 e 27 anos a mais afetada. Os resultados indicaram que os valores e crenças dos indivíduos não foram afetados pela redução da frequência à igreja, tornando a segunda hipótese, a da explicação orientada ao consumo, a mais satisfatória em relação à Teoria da Secularização que postula um abandono mais profundo dos valores e crenças. Quanto à terceira hipótese, os dados não permitiram investigá-la, pois, o crescimento econômico, ainda que tenha aumentado o emprego, resultou na reduçáo da quantidade de horas trabalhadas, náo sendo possível atribuir o declínio de frequência à igreja a simples falta de tempo.

Noland (2003), por sua vez, aponta que, em determinadas crenças religiosas, os aumentos na frequência da igreja tendem a reduzir o crescimento econômico. Por outro lado, para uma determinada frequência à igreja, o aumento de algumas crenças religiosas principalmente o céu, o inferno e a vida após a morte - tendem a aumentar o crescimento econômico. Em outras palavras, o crescimento econômico depende principalmente da extensão da crença em relação à pertença. Os autores também encontram alguma indicação de que o medo do inferno é mais potente positivamente para o crescimento econômico do que a perspectiva do céu.

Já Galbraith e Galbraith (2007), estudam o comportamento empreendedor, pressupondo que a atividade empreendedora também é relevante para o crescimento econômico tanto quanto a atividade de consumo. Utilizaram o conceito de religiosidade intrínseca de Allport (1950) e concluem que a religiosidade do indivíduo está positivamente relacionada a atividade empreendedora que está relacionada ao crescimento.

Young (2009) tenta aplicar um modelo de incerteza à religiâo, ainda em fase embrionária, mas contendo uma amostra intercontinental e sem especificar a religião. $\mathrm{O}$ autor sustenta que o poder computacional moderno permite aos pesquisadores estimar um grande número de modelos plausíveis, mas apenas algumas dessas estimativas são publicadas. $\mathrm{O}$ resultado é uma severa assimetria de informaçóes entre analista e leitor. O processo de modelagem aplicada produz uma gama muito maior de estimativas do que é sugerido pelos erros padrão habituais ou intervalos de confiança. $\mathrm{O}$ autor demonstrou isso usando as pesquisas de Barro e McCleary sobre religião e crescimento econômico. Notouse que alteraçôes pequenas e sensíveis em suas especificaçóes de modelo produzem grandes alteraçóes nos resultados: os resultados ficam inconsistentes ao longo do tempo, e a estratégia das variáveis instrumentais acaba sofrendo com um conjunto fraco de instrumentos. $\mathrm{O}$ autor afirma que as descobertas empíricas devem ser avaliadas não apenas por sua significância, mas também por sua robustez à especificação do modelo.

O desenvolvimento econômico é também um tema recorrente entre os artigos mais citados do século 21. Montalvo e Reynal-Querol (2003) analisam o efeito da diversidade religiosa no desenvolvimento econômico. Argumentam que o índice de polarização religiosa é mais apropriado para medir o efeito de um conflito potencial no desenvolvimento econômico do que o índice de fragmentação tradicional. Já Mangeloja (2005) analisou 
como as instituições morais, religiōes e a ética - como confiança e honestidade, por exemplo - afetam o desenvolvimento econômico. Evidencias sugerem que as crenças religiosas possuem maior relevância do que a frequência religiosa. A eficiência da produçáo religiosa, contendo aspectos de crença e atividade, náo foi estatisticamente significante nos dados da amostra, exceto na Finlândia. O motivo dessa exceção é que o nível da crença religiosa na Finlândia é historicamente maior.

Nos estudos de McCleary e Barro (2006a; 2006b), especificamente, analisaram o quanto a presença na igreja e as crenças religiosas impactam na educação e urbanizaçáo. Os resultados evidenciaram associação positiva à educaçáo, mas negativa à urbanizaçáo. Os autores estáo entre os mais citados, e têm sido referência para as demais pesquisas. Tanto é que Durlauf, Kourtellos e Tan (2012), avaliando suas reivindicaçóes em termos de replicabilidade e robustez, concluem que, no geral, suas análises atendem ao padrão de replicabilidade estatística, embora não perfeitamente.

McCleary (2008), num artigo teórico, afirmou que certas religióes, como o judaísmo, valorizam mais a educação. A provável razão é que os judeus investiram em capital humano porque não tinham permissão para possuir propriedades ou, se existissem, eram direitos inseguros. Solt, Haber e Grant (2011) investigam qual o efeito da desigualdade econômica de um país sobre a religiosidade de sua população. Também analisam, dentro do contexto da desigualdade, se a religiáo serve de fonte de conforto para os mais pobres ou se, em contrapartida, acaba servindo de ferramenta de controle social para a classe mais rica e poderosa. A amostra é americana. Os resultados sugerem que a desigualdade econômica tende a aumentar a religiosidade da sociedade, independentemente de renda. Os autores afirmam que isso apoia a Teoria do Poder Relativo, na qual, quanto maior a desigualdade, maior a religiosidade, o que atrai pessoas de renda mais alta que visam usar a religiáo para moldar as atitudes e crenças dos menos abastados.

Tangenciando o tema do Desenvolvimento, Bénabou, Ticchi e Vindigni (2013) sugerem três modelos de política econômica que levam em conta as variáveis religião e economia. Os modelos são o "europeu ocidental", o "teocrático" e o "americano". O modelo europeu ocidental é secularizado, a ciência é desimpedida enquanto que a religião é passiva e em declínio. Há altos níveis de impostos e transferências. No modelo teocrático o conhecimento tende a ser estagnado, a religiosidade é extrema, não há esforço de modernização e os gastos públicos são elevados em bens públicos religiosos. Por fim, o modelo americano, que combina progresso científico e religiosidade estável na qual as instituiçóes religiosas se engajam em adaptação doutrinária. Apresenta baixos impostos gerais, mas há leis sociais e vantagens fiscais que beneficiam cidadãos religiosos. Os autores concluem que o aumento da desigualdade pode levar alguns ricos a formar alianças religiosas e de direita política com os religiosos pobres, podendo bloquear descobertas e ideias que venham a corroer suas crenças.

O debate sobre a tese weberiana ainda tem lugar na pesquisa de alto impacto. Hayward e Kemmelmeier (2011) analisam o impacto do protestantismo sobre a atitude pró-mercado, tendo evidenciado a associação positiva entre ser protestante e decisóes prómercado. 
Renneboog e Spaenjers (2012), com uma amostra holandesa, identificam que as famílias católicas são mais avessas ao risco, enquanto que famílias protestantes são mais dadas ao risco e possuem maior senso de responsabilidade financeira. Também concluem que as famílias religiosas são mais propensas a economizar do que as famílias não religiosas, e as famílias católicas investem com menos frequência no mercado de açóes. Já Barker e Carman (2000), ao analisarem as atitudes econômicas dos protestantes, numa amostra intercontinental, concluíram que os resultados empíricos apoiam a tese weberiana e acrescentam que a crença religiosa atua como um agente exógeno dos principais valores políticos.

O estudo de Benjamin, Choi e Fisher (2016) testou a identidade religiosa dos protestantes e católicos quanto à contribuição para os bens públicos. Concluíram que quanto maior a identidade do protestante, maior será sua contribuição para os bens públicos. Afirmam que não há evidências de relação entre religiosidade e desutilidade do trabalho. Por fim, num dos poucos trabalhos de amostra africana, Meagher (2009) analisa os movimentos religiosos e a governança econômica. $\mathrm{O}$ autor afirma que em vez de representar um retorno aos impulsos ocultistas ou patrimoniais, novos movimentos religiosos revelam tendências nitidamente weberianas.

Paldam (2001) fez uma ampla análise da relação entre corrupção e as mais diversas religiōes. A análise partiu de um modelo econômico de corrupção. No modelo, se pressupõe que países mais pobres tendem a um nível mais alto de corrupção. Conforme esses países vão crescendo e se tornando mais ricos, a corrupção tende a cair. $\mathrm{O}$ objetivo da análise foi mostrar se os fatores culturais formados por diferenças religiosas podem explicar o índice de corrupção. Verificou-se que dois grupos religiosos tendem a diminuir a corrupção, o cristianismo reformado e religióes tribais. Surpreendentemente, o autor evidenciou maior grau de corrupção entre budistas e católicos, o que contraria as consideraçóes weberianas sobre um apego materialista ser maior entre os protestantes.

Lelkes (2006), ao estudar sobre a degustação da liberdade, felicidade e religião, em uma amostra da Hungria, afirma que o envolvimento religioso contribui positivamente para o bem-estar dos indivíduos e o dinheiro não é uma fonte tão importante de felicidade para os religiosos. Já Bansak, Hainmueller e Hangartner (2016), ao estudarem a relação entre religiosidade e preocupaçóes humanitárias, concluíram que os requerentes cristãos de asilos para idosos recebem maior apoio público que os muçulmanos. Esses resultados sugerem que as preferências do público em relação aos solicitantes de asilo têm relação com preconceitos religiosos. Essas preferências são semelhantes entre os entrevistados de diferentes idades, níveis de educação, renda e ideologias políticas, além dos países pesquisados.

Lancee e Dronkers (2011) estudaram a relação entre diversidade étnica, religiaao e convívio com vizinhos. Eles atribuem à religiosidade, a boa qualidade no contato entre os vizinhos da localidade pesquisada. Guiso, Sapienza e Zingales (2003), por sua vez, buscaram identificar a relação entre a intensidade das crenças religiosas e as atitudes econômicas como cooperação, governo, mulheres trabalhadoras, regras legais, parcimônia e economia de mercado. Concluíram que, em média, as crenças religiosas estão associadas positivamente a maior renda e crescimento per capita. Entretanto, evidenciaram que pessoas religiosas também tendem a ser mais racistas e menos favoráveis em relação às mulheres que trabalham. 
Já Lehrer (2004a) analisa os efeitos da religião em vários comportamentos econômicos e demográficos de indivíduos e famílias nos Estados Unidos, incluindo a escolha de parceiro conjugal, formação e dissolução de sindicatos, fertilidade, alocação de tempo feminino, educação, salários e riqueza. Ele conclui que a afiliação religiosa afeta o comportamento econômico e demográfico devido ao seu impacto nos custos e benefícios de muitas decisóes inter-relacionadas que as pessoas tomam ao longo do ciclo da vida. Além disso, para comportamentos que pertencem a famílias de casais, a afiliação religiosa é importante porque é uma característica complementar no contexto do casamento.

Por sua vez, Brañas-Garza e Neuman (2004) analisam a relação entre religiosidade - considerando crenças, oração e presença na igreja - e algumas variáveis socioeconômicas. Os dados evidenciaram que: a) as mulheres são mais religiosas que os homens; b) a atividade religiosa aumenta com a idade; c) existe uma relação positiva significativa entre escolaridade e religiosidade; d) a religiosidade está positivamente relacionada à exposiçáo a atividades religiosas durante a infância; e) a atividade religiosa masculina é afetada positivamente pelo estado civil - ser casado com uma esposa católica - e pelo número de filhos em casa. Os resultados também demonstram a importância do "motivo da salvação" para ambos os sexos e a presença do "motivo utilitário profissional" no comportamento religioso masculino.

Por fim, Daniels e Ruhr (2005) estudam o impacto da afiliação religiosa nas preferências de política comercial e de imigração. Concluem que católicos e protestantes fundamentalistas têm maior probabilidade de preferir políticas de restrição às importaçôes e à imigração.

Estudos sobre a religiáo islâmica e hindu também tiveram o seu lugar entre os 50 artigos mais citados. Campante e Yanagizawa-Drott (2015) analisaram a relação entre a fé islâmica, a felicidade e o crescimento econômico. Para os autores, as práticas religiosas podem afetar as opçóes de oferta de trabalho de maneiras que têm implicaçóes negativas no desempenho econômico, mas que, no entanto, aumentam o bem-estar subjetivo entre os seguidores.

Já Kuran (2004), num artigo teórico, reflete sobre o papel do pluralismo jurídico islâmico na ascensão econômica das minorias religiosas do Oriente Médio. Chantler, Gangoli e Hester (2009) pesquisaram a influência do Islamismo em casamentos forçados entre fiéis da mesma religião no Reino Unido. Argumentaram que, embora as comunidades sul-asiáticas e muçulmanas são percebidas como as principais responsáveis por casamentos forçados, demonstraram que a gama de comunidades nas quais o casamento forçado ocorre é muito maior.

Panagariya e More (2014) comparam hindus e islâmicos na pobreza de grupos sociais da Índia. Os dados analisados foram dos anos 1993-1994, 2004-2005, 2009-2010 e 2011 2012. Independentemente de dividir os dados por grupos sociais, religiosos ou econômicos, por estados ou por áreas rurais e urbanas, a pobreza diminuiu significativamente entre 19931994 e 2011-2012, com uma aceleração substancial durante o período de crescimento mais rápido de 2004-2005 a $2011-2012$. As taxas de pobreza entre minorias em desvantagem diminuíram mais rapidamente, de modo que a diferença nas taxas de pobreza entre eles e a população em geral diminuiu. Em 7 dos 16 estados da Índia, a taxa de pobreza dos muçulmanos é menor que que a dos hindus. 
Por fim, Borooah, Dubey e Iyer (2007) pesquisam sobre religião, emprego, casta e situação econômica entre os hindus da Índia. Eles investigam o efeito da reserva de empregos na melhoria das oportunidades econômicas de pessoas pertencentes à minorias de hierarquia mais baixa ${ }^{3}$. Concluíram que as políticas afirmativas de reserva de emprego resultou num impulso de $5 \%$ para as minorias mais desfavorecidas.

Vários artigos são difícil classificação devido ao alto grau de especificidade em seus temas e/ou objetos de pesquisa. Brown (2000), por exemplo, estuda a relação entre religião e atividade econômica de sul-asiáticos do Reino Unido. O autor relata que a literatura antropológica e sociológica aponta para a importância da religião como base para a compreensão da natureza diversa dessa população. A análise de sua pesquisa relata diferenças substanciais entre subgrupos religiosos - por idade e sexo - em uma série de medidas-chave, incluindo: diferenças na proporção economicamente ativa; diferenças na proporção de economicamente ativos que obtêm emprego com sucesso; entre os empregados, diferenças no tipo de emprego ocupado e na renda reportada.

Num trabalho teórico, Chaney (2013) aborda o espinhoso tema das revoltas na regiáo do Rio Nilo, os choques econômicos resultantes e a disputa de poder político tendo como pano de fundo elementos religiosos. Usando séculos de dados das inundaçóes do Nilo, o artigo relata que, durante as inundaçóes do Nilo, a autoridade religiosa de mais alto escalão do Egito era menos provável de ser substituída e as alocações relativas às estruturas religiosas aumentavam.

Barret e Richards (2004), por meio de métodos arqueológicos, ilustram como as contingências ambientais e culturais locais se relacionam com uma tendência pan-européia de pesca mais intensiva no final do primeiro milênio. As causas desses desenvolvimentos provavelmente envolveram uma complexa relação entre etnia, gênero, práticas de jejum cristão, crescimento populacional, comércio de peixes de longo alcance e mudanças ambientais.

Lehrer (2004b) estuda a relação entre religião e formação sindical. O autor utiliza como pressuposto a ideia de que a fé de uma jovem mulher tem efeitos importantes nos custos e/ou benefícios subjetivos de muitas decisóes que ela toma ao longo do ciclo da vida, incluindo escolaridade, emprego e fertilidade. Com base nessas evidências, ele desenvolve hipóteses sobre os padrôes de entrada em casamento e coabitação para os principais grupos religiosos nos Estados Unidos: protestantes principais, protestantes conservadores, católicos, mórmons, judeus e não afiliados. Os resultados empíricos, baseados em mulheres jovens da Pesquisa Nacional de Crescimento Familiar de 1995, geralmente apoiam as hipóteses.

Aditjondro (2001) faz um trabalho teórico onde descreve a violência e tensão étnico-religiosa por interesses políticos nas Ilhas Moluscas. Não ficou de fora o tema da educação, Cohen-Zada (2006), investigando a relação entre educação e identidade religiosa no cristianismo americano, concluíram que quando as minorias na população cresce, e as

3 Os autores utilizam os termos castas programadas e tribos programadas para diferenciar os diferentes grupos sociais da Índia, realidade pouco conhecida e de difícil compreensão no Ocidente. 
influências externas se tornam menos ameaçadoras, a educação tende a afrouxar mais em relação aos valores religiosos.

Já Bankston e Zhou (2000), numa amostra de dois países, Laos e Vietnã, estudaram a relação entre congregacionalismo e mobilidade socioeconômica. Para os autores, embora a preservação cultural fosse uma função manifesta essencial da igreja e do templo, esses dois também serviam uma função latente de expressar e promover a mobilidade socioeconômica. Tanto o caráter voluntário das organizaçóes quanto a mobilidade a elas associada tenderam, ironicamente, a remodelar as organizaçóes em formas congregacionais não tradicionais.

Fink (2008) faz uma reflexão sobre a influência da religião na opinião sobre os embrióes. Já Uelmen e Bruni (2006) pesquisam sobre valores religiosos e a tomada de decisão corporativa. Afirmam que, recentemente, a literatura jurídica, econômica e administrativa começou a explorar as inúmeras questóes e preocupaçóes complexas que surgem com a perspectiva de integrar perspectivas, valores e estruturas religiosas na vida dos negócios. Concluem que, em todos os aspectos da investigação, a mudança de princípios teóricos abstratos para a implementação prática parece ser extremamente difícil.

Num raro trabalho de amostra africana, Asadullah e Chaudhury (2010) analisam os valores sociais das escolas religiosas e o quanto elas influenciam nas atitudes econômicas. $\mathrm{O}$ artigo utiliza dados sobre mulheres graduadas em escolas secundárias registradas na zona rural de Bangladesh e testa se existem lacunas de atitude por tipo de escola e quais fatores específicos do professor explicam essas lacunas. Evidenciou-se que graduadas em escolas religiosas diferem nas atitudes associadas a questóes como mães que trabalham, fertilidade desejada e educação superior para meninas, quando comparadas com as colegas seculares. Por outro lado, a educação religiosa está associada a atitudes que conduzem à democracia.

Impressionante observar que a América Latina apareça como amostra apenas uma vez entre os artigos de maior impacto. Chesnut (2003) toca na delicada questão sobre os limites da religião no atendimento de anseios materiais e econômicos dos fieis em detrimento dos anseios existenciais. Evidencia que, diferente do cristianismo tradicional, que não utiliza curas e expressóes pneumáticas (manifestações de espíritos nos cultos), o cristianismo pentecostal, em especial a Igreja Católica Carismática, tendem a atenuar a formalidade em seus cultos, apelando sensivelmente para o uso de fenômenos miraculosos, promovendo uma elevação na quantidade de fieis. Por sua vez, religióes que não oferecem cura sobrenatural e resolução de problemas terrenos, não tem conseguido prosperar no crescimento de fieis na mesma proporção que as religióes pneumáticas. $\mathrm{O}$ autor prefere não sugerir que as religiōes pneumáticas ofereçam essa forma de culto com o simples propósito de crescimento de fieis em vez deste crescimento ser apenas um resultado de seu entendimento genuíno de como deve ser a forma de culto. Independente disso, os números sugerem que os anseios econômicos têm forte apelo na escolha de uma religião.

A China é representada pelo estudo de Lang, Chang e Ragvald (2005) que tratam da relação cada vez maior entre o marketing religioso e o uso dos templos nesse processo. Para os autores, os templos chineses disputam os fiéis e são participantes ativos da economia religiosa. Os gerentes dos novos templos mais bem-sucedidos se envolvem na tomada de decisões estratégicas sobre marketing, promoção, inovação e atividades públicas para aumentar a visibilidade e o apelo de seus templos. 
Mafimisebi e Oguntade (2010) analisam a relação entre o uso de remédios fitoterápicos, nível sociocultural e práticas mágico-religiosas numa amostra de agricultores do Sudoeste da Nigéria. Os habitantes rurais agrários da Nigéria produzem cerca de 95\% dos produtos alimentares cultivados localmente. A baixa acessibilidade à medicina ortodoxa por parte dos moradores rurais e sua necessidade de manter-se saudável para ser economicamente produtivo levaram à dependência da medicina tradicional. $O$ fato de o conceito de doença dos praticantes de medicina tradicional estar em um plano mais amplo em relação aos praticantes de medicina ortodoxa, culminou em algumas práticas socioculturais e mágico-religiosas observadas na preparação e uso de fitoterápicos para a gestão da saúde dos agricultores. Isso provavelmente explica o surgimento e a observância de algumas práticas socioculturais e sobrenaturais ou mágico-religiosas que se tornaram parte integrante da prática da medicina tradicional na Nigéria.

Terzidou, Stylidis e Szivas (2008) analisam a percepção local dos moradores gregos sobre o turismo religioso e seus impactos socioeconômicos na ilha de Tinos. O turismo e a religiâo estão historicamente relacionados através da instituição de peregrinação, da qual mais tarde emergiu o fenômeno do turismo religioso. Concluíram que a maioria dos residentes recebe turistas religiosos na ilha e considera os impactos socioeconômicos positivos. Por fim, Yuchtman-Yaar e Alkalay (2007), ao comparar protestantes, católicos e islâmicos, analisam a influência da Cultura e Economia na adoção de valores modernos. Os resultados, entretanto, não foram robustos o suficiente para estimar os efeitos das variáveis.

Wuthnow (2005) ainda acrescenta que as pesquisas recentes concordam, em grande medida, que o comportamento econômico é menos guiado por preferências internas e mais por negociaçóes ativas que ocorrem por meio de mensagens e símbolos. Além disso, uma tendência das pesquisas futuras é incluir mais processos interativos que envolvem recursos econômicos, grupos de interesse, acordos de poder, mídia, papéis de gênero e instituições religiosas, em vez de apenas supor que as relações entre condições econômicas e comportamento religioso possam ser entendidas na esfera da psicologia social da sociedade. $\mathrm{O}$ ponto de discordância, conforme o autor, dizem respeito a quais desses vários fatores enfatizar, se os modelos de escolha racional são úteis ou não, e quanto pensar sobre a autonomia relativa da religião em relação às condiçôes econômicas ou sua dependência dessas condiçóes.

O autor critica parte da pesquisa recente por julgar que esses estudos têm abandonado a pretensão de ser científica. Particularidades substituem a busca por universais e a descrição tem precedência sobre a análise causal. Isso dificulta dizer se o trabalho recente representa ou não progresso. Continua-se buscando evidências por questóes centrais que marcaram estudos anteriores. Contribuem preenchendo lacunas, abordando regularidades empíricas intrigantes e ilustrando a complexidade do comportamento humano. Também se esforçam em descobrir aspectos da interação social que podem ser entendidos em termos de modelos simples.

\section{Consideraçóes Finais}

Este artigo teve como objetivo analisar o estado da arte da pesquisa sobre religiosidade e economia, revisando e analisando os artigos mais citados publicados entre 2000 e 2019. 
Evidencia-se que o interesse pela capacidade da religiáo impactar o crescimento econômico e o desenvolvimento econômico continua elevado. Dentre estes, seis artigos abordam o crescimento econômico e nove abordam o desenvolvimento econômico. Barro e McCleary são os autores de maior referência, são sempre citados, e diversos trabalhos se empenham na confirmação ou refutação empírica de seus resultados, ou tentam replicar seus estudos em outros contextos. Os resultados, apesar de não unânimes, apoiam consistentemente a ideia de que existe associação positiva entre certas religióes principalmente entre o protestantismo e o crescimento e desenvolvimento econômico. Uma exceção, Hirschle (2010), confirmou empiricamente que o crescimento econômico está significativamente associado ao declínio da prática religiosa. Também há de se ressaltar que os pesquisadores, no geral, evitam atribuir relaçáo de causalidade entre religiosidade e crescimento/desenvolvimento econômico, preferindo utilizar o conceito de correlação ou associação positiva/negativa em suas consideraçôes.

Notou-se que a separação dos artigos por temas, aparentemente um exercício simples, tornou-se algo um tanto temerário e complicado. Isso porque, os artigos trabalham os conceitos de formas bem distintas as vezes. Alguns artigos focam em crescimento ou desenvolvimento econômico, enquanto outros utilizam ambos os conceitos como sinônimos. Outro exemplo dessa transversalidade dos temas é que a validade da tese weberiana, importante tema teórico, embora não tenha ficado de fora da pesquisa de alto impacto, na verdade também trata do crescimento econômico, só que, com foco na sua relação com a ética protestante.

Observa-se também, que, o conceito de religiosidade intrínseca de Allport (1950), bem utilizada para medir a religiosidade em estudos éticos e religiosos da área da Administração (VITELL; PAOLILLO; SINGH, 2005; ARLI, 2017; PACE, 2014; SCHNEIDER; KRIEGER; BAYRAKTAR, 2011), é menos utilizada no âmbito da economia. Além disso, surpreende o fato de Young (2009) ser o único autor entre os 50 mais citados que tenta uma modelagem. A natureza complexa da variável religião/religiosidade parece afastar ainda as tentativas de construção teórica. A presença de microanálises parece reforçar isso (GUISO; SAPIENZA; ZINGALES, 2003).

Outro resultado surpreendente é a de Paldam (2001) que evidenciou maior grau de corrupção entre budistas em relação aos protestantes, considerando o maior apego materialista tâo vinculada aos protestantes desde Weber.

Um fator negativo na pesquisa de alto impacto sobre religiosidade e economia é a baixa representatividade da América Latina, incluindo aí o Brasil. Apenas Chesnut (2003), que analisa o crescimento da renovação carismática da Igreja Católica, representa a amostragem da América Latina. Considerando que a América Latina e a África são continentes de grande contingente religioso (CARVALHO, 1999), quando as pesquisas de maior impacto desprezam essa amostra, a tendência é haver forte viés em seus resultados. Conforme Gadelha e Arantes Junior (2017), a literatura sobre religiosidade e economia ainda é escassa no Brasil, possivelmente pela dificuldade de quantificar o construto.

Por fim, é possível afirmar que a pesquisa sobre religiosidade no contexto da vida econômica ainda tem muito a amadurecer. Similar ao embate ideológico, que disputa com o amadurecimento científico, a existência de tantas religiōes e denominações religiosas, 
possivelmente atua como um ruído entre os pesquisadores que desejam se engajar na área. Tal ruído tem várias fontes, seja a forma subjetiva com que um entrevistado responde sobre sua fé, seja pelas diferenças tấo grandes que dificultam conceituar o cristianismo, catolicismo, protestantismo, afinal, são termos que induzem a ideia de uma unidade, que na prática, não existe. Além disso, a pesquisa recente sobre religiosidade apresenta forte caráter microanalítica e baixa solidez teórica, quase não havendo esforços na construção de modelos teóricos.

Esta pesquisa tem suas limitaçóes. Em primeiro lugar, não se pretendeu ser exaustivo na leitura completa dos artigos levantados. A escolha pela análise dos 50 artigos mais citados entre 2000 e 2019, talvez tenha tornado mais claro alguns interesses, também ganha em praticidade, mas talvez empobreça um pouco a contribuição total da pesquisa. Para pesquisas futuras fica a sugestáo de uma análise mais profunda, por meio de uma bibliometria com utilização de métodos quantitativos mais robustos. Além disso, seria interessante replicar alguns testes empíricos, realizados com amostras intercontinentais ou europeias, no Brasil, América do Sul e África. Assim será possível fazer comparaçóes tendo em vista contextos tâo diferentes de renda e distribuição de renda, o que daria um feedback maior em relação ao que já está estabelecido.

\section{Referências}

ADITJONDRO, G. J. Guns, pamphlets and handie-talkies: how the military exploited local ethno-religious tensions in Maluku to preserve their political and economic privileges. In. ALLPORT, G. W. The individual and religion. Newyork: Mac Millan, 1950.

ALLPORT, G. W.; ROSS, J. M. Personal religious orientation and prejudice. Journal of Personality and Social Psychology, v. 5, n. 4, p. 432-443, 1967.

ARLI, D. Does ethics need religion? Evaluating the importance of religiosity in consumer ethics. Marketing Inteligence \& Planning, v. 35, n. 2, p. 205-221, 2017.

ASADULLAH, M. N.; CHAUDHURY, N. Religious Schools, Social Values, and Economic Attitudes: Evidence from Bangladesh. World Development, v. 38, n. 2, p. 205-217, 2010.

AYDEMIR, M.; EGILMEZ, O. An important antecedent of ethical/unethical behavior: religiosity. Eurasian Journal of Business and Economics, v. 3, n. 6, p. 71-84, 2010.

AZZI, C.; EHRENBERG, R. G. Household allocation of time and church attendance. Journal of Political Economy, v. 83, n. 1, p. 27-56, 1975.

BANKSTON, C. L.; ZHOU, M. De facto congregationalism and socioeconomic mobility in Laotian and Vietnamese immigrant communities: A study of religious 
institutions and economic change. Review of Religious Research, v. 41, n. 4, p. 453$470,2000$.

BANSAK, K.; HAINMUELLER, J.; HANGARTNER, D. How economic, humanitarian, and religious concerns shape European attitudes toward asylum seekers. Science, v. 354, n. 6309, p. 217-222, 2016.

BARRET, J. H.; RICHARDS, M. P. Identity, gender, religion and economy: new isotope and radiocarbon evidence for marine resource intensification in early historic Orkney, Scotland, UK. European Journal of Archaeology, v. 7, n. 3, p. 249-271, 2004.

BARRO, R. J.; MCCLEARY, R. M. Religion and Economic Growth across Countries. American Sociological Review, v. 68, n. 5, p. 760-781, 2003.

BARKER, D. C.; CARMAN, C. J. The spirit of capitalism? Religious doctrine, values, and economic attitude constructs. Political Behavior, v. 22, n. 1, p. 1-27, 2000.

BECKER, G. S. Investment in Human Capital: A Theoretical Analysis. Journal of Political Economy, v. 70, n. 5, p. 9-49, 1962.

BECKER, S. O.; WOESSMANN, L. (2009). Was Weber Wrong? A Human Capital Theory of Protestant Economic History. Quarterly Journal of Economics, v. 124, n. 2, p. 531-596, 2009.

BÉNABOU, R.; TICCHI, D.; VINDIGNI, A. Forbidden Fruits: The Political Economy of Science, Religion, and Growth. Working Paper, Princeton University, 2013.

BENJAMIN, D, J.; CHOI, J. J.; FISHER, G. Religious Identity and Economic Behavior. Review of Economics and Statistics, v. 98, n. 4, p. 617-637, 2016.

BERNARDELLI, L. V.; MICHELLON, E. A religião e o crescimento econômico: uma análise para o Paraná de 1991 a 2010. In PAVAN, L. S. (Org.) As teorias econômicas e a economia aplicada. Ed. Atena, 2018.

BJARNASON, D. Concept analysis of religiosity. Home Health Care Management and Practice, v. 19, n. 5, p. 350-355, 2007

BLUM, U.; DUDLEY, L. Religion and economic growth: was Weber right? Journal of Evolutionary Economics, v. 11, n. 2, p. 207-230, 2001.

BOROOAH, V. K.; DUBEY, A.; IYER, S. The Effectiveness of Jobs Reservation: Caste, Religion and Economic Status in India. Development and Change, v. 38, n. 3, p. 423-445, 2007. 
BRAÑAS-GARZA, P.; NEUMAN, S. Analyzing Religiosity within an Economic Framework: The Case of Spanish Catholics. Review of Economics of the Household, v. 2, n. 1, p. 5-22, 2004.

BROWN, M. S. Religion and economic activity in the South Asian population. Ethnic and Racial Studies, v. 23, n. 6, p. 1035-1061, 2000.

CAMPANTE, F.; YANAGIZAWA-DROTT, D. Does Religion Affect Economic Growth and Happiness? Evidence from Ramadan. The Quarterly Journal of Economics, v. 130, n. 2, p. 615-658, 2015.

CARVALHO, J. J. de. Um espaço público encantado: pluralidade religiosa e modernidade no Brasil. Série Antropologia - UnB, v. 249, 1999.

CHISWICK, B. R. The earnings andhuman capital of American Jews. Journal of Human Resources, v. 18, n. 3, p. 313-336, 1983.

COHEN-ZADA, D. Preserving religious identity through education: Economic analysis and evidence from the US. Journal of Urban Economics, v. 60, n. 3, p. 372-398, 2006.

DANIELS, J. P.; RUHR, M. V. D. God and the global economy: religion and attitudes towards trade and immigration in the United States. Socio-Economic Review, v. 3, n. 3, p. 467-489, 2005.

EISENSTADT, S. N. The Protestant Ethic and Modernization: a Comparative View. Basic Books, New York, 1968.

EKELUND JUNIOR, R. B.; HÉBERT, R. F; TOLLISON, R. D. An Economic Analysis of the Protestant Reformation. Journal Of Political Economy, v. 110, n. 3, p. 646-671, 2002.

ELLISON, C. G. Religious involvement andsubjective well-being. Journal of Health andSocial Behavior, v. 32, n. 1, p. 80-99, 1991.

EVANS, T. D.; FRANCIS, T.; CULLEN, R.; GREGORY, D.; VELMER, S.; BURTON Jr. Religion andcrime reexamined: The impact of religion, secular controls, and social ecology on adult criminality. Criminology, v. 33, n. 2, p. 195-224, 1995.

FREEMAN, R. B. Who escapes? The relation of churchgoing andother background factors to the socioeconomic performance of black male youths from inner-city tracts. In RICHARD, B.

GADELHA, S. R. de B.; ARANTES JUNIOR, P. F. (2017). Economia da religião: uma resenha sobre religião e educação. Ciências da Religião: história e sociedade, v. 15, n. 1, p. 59-82, 2017. 
CHANEY, E. Revolt on the Nile: Economic Shocks, Religion, and Political Power.

Econometrica, v. 81, n. 5, p. 2033-2053, 2013.

CHANTLER, K.; GANGOLI, G.; HESTER, M. Forced marriage in the UK: Religious, cultural, economic or state violence? Critical Social Policy, v. 29, n. 4, p. 587-612, 2009.

CHESNUT, R. A. A Preferential Option for the Spirit: The Catholic Charismatic Renewal in Latin America's New Religious Economy. Latin American Politics and Society, v. 45, n. 1, p. 55-85, 2003.

DURLAUF, S. N.; KOURTELLOS, A.; TAN, C. M. Is God in the Details? A Reexamination of the Role of Religion in Economic Growth. Journal of Applied Econometrics, v. 27, n. 7, p. 1059-1075, 2012.

FINK, S. Politics as Usual or Bringing Religion Back In? Comparative Political Studies, v. 41, n. 12, p. 1631-1656, 2008.

GALBRAITH, C. S.; GALBRAITH, D. M. An empirical note on entrepreneurial activity, intrinsic religiosity and economic growth. Journal of Enterprising Communities:

People and Places in the Global Economy, v. 1, n. 2, p. 188-201, 2007.

GRIER, R. The Effect of religion on economic development: a cross-national study of 63 former colonies. Kyklos, v. 50, n. 1, p. 47-62, 1997.

GUISO, L.; SAPIENZA, P.; ZINGALES, L. People's opium? Religion and economic attitudes, Journal of Monetary Economics, v. 50, p. 225-282, 2003.

HAYWARD, R. D.; KEMMELMEIER, M. Weber Revisited. Journal of Cross-Cultural Psychology, v. 42, n. 8, p. 1406-1420, 2011.

HIRSCHLE, J. From Religious to Consumption-Related Routine Activities? Analyzing Ireland's Economic Boom and the Decline in Church Attendance. Journal for the Scientific Study of Religion, v. 49, n. 4, p. 673-687, 2010.

HUNTINGTON, S. P. The Clash of Civilizations and the Remaking of World Order. New York: Simon \& Schuster, 1996.

IANNACCONE, L. R. Introduction to the economics of religion. Journal of Economic Literature, v. 36, n. 3, p. 1465-1496, 1998.

INGLEHART, R. Trust, well-being and democracy. In: WARREN, M. (Ed.), Democracy and Trust. Cambridge University Press, New York, Cambridge: 88-120, 1999.

INGLEHART, R.; BAKER, W. E. Modernization, Cultural Change, and the Persistence of Traditional Values. American Sociological Review, v. 65, n. 1, p. 19-51, 2000. 
JOHNSON, B. R.; JANG, S. J.; LARSON, D. B.; LI, S. D. Does adolescent religious commitment matter? A reexamination of the effects of religiosity on delinquency. Journal of Research in Crime and Delinquency, v. 38, n. 1, p. 22-44, 2001.

KURAN, T. The Economic Ascent of the Middle East's Religious Minorities: The Role of Islamic Legal Pluralism. Journal of Legal Studies, v. 33, p. 475-515, 2004.

LA PORTA, R.; LOPEZ-DE-SILANES, F.; SHLEIFER, A.; VISHNY, R. W. Trust in large organizations. American Economic Review, v. 87, n. 2, p. 333-338, 1997.

LANCEE, B.; DRONKERS, J. Ethnic, Religious and Economic Diversity in Dutch Neighbourhoods: Explaining Quality of Contact with Neighbours, Trust in the Neighbourhood and Inter-Ethnic Trust. Journal of Ethnic and Migration Studies, v. 37, n. 4, p. 597-618, 2011.

LANDES, D. The Wealth andPoverty of Nations. Little, Brown, andCompany, London, 1998.

LANG, G.; CHANG, S. C.; RAGVALD, L. Temples and the Religious Economy. Interdisciplinary Journal of Research on Religion, v. 1, n. 1, 2005.

LAVELEYE, E. Do Futuro dos Povos Católicos: Estudo de Economia Social. 2 ed. FERREIRA, M. V. (Trad.). São Paulo: Casa Editora Presbiteriana, 1985.

LEHRER, E. L. Religion as a Determinant of Economic and Demographic Behavior in the United States. Population and Development Review, v. 30, n. 4, p. 707-726, $2004 a$.

LEHRER, E. L. The Role of Religion in Union Formation: An Economic Perspective. Population Research and Policy Review, v. 23, n. 2, p. 161-185, 2004 b.

LELKES, O. Tasting freedom: Happiness, religion and economic transition. Journal of Economic Behavior \& Organization, v. 59, n. 2, p. 173-194, 2006.

LUTERO, M. Martinho Lutero: V 1 - Os Primórdios Escritos de 1517 a 1519. 2. ed. Canoas: Editora da Ulbra, 2004. 469 p. (Obras Selecionadas). Comissão Interluterana de Literatura São Leopoldo, 2004.

MAFIMISEBI, T. E.; OGUNTADE, A. E. Preparation and use of plant medicines for farmers' health in Southwest Nigeria: socio-cultural, magico-religious and economic aspects. Journal of Ethnobiology and Ethnomedicine, v. 6, n. 1, p. 1-9, 2010.

MAGILL, G. Theology in Business Ethics: Appealing to the Religious Imagination. Journal of Business Ethics, v. 11, n. 2, p. 129-135, 1992. 
MANGELOJA, E. Economic growth and religious production efficiency. Applied Economics, v. 37, n. 20, p. 2349-2359, 2005.

MARX, K. Contribution to the Critique of Hegel's Philosophy of Right: Introduction. Works of Marx, 1843.

MCCLEARY, R. M.; BARRO, R. J. Religion and Political Economy in an International Panel. Journal for the Scientific Study of Religion, v. 45, n. 2, p. 149-175, 2006 a.

MCCLEARY, R. M.; BARRO, R. J. Religion and Economy. Journal of Economic Perspectives, v. 20, n. 2, p. 49-72, 2006 b.

MCCLEARY, R. M. Religion and economic development. Stanfort University, Hoover Institution, 2008.

MCCLEARY, R. M. (2011). The Oxford Handbook of the Economics of Religion. New York: Oxford University Press, 2011.

MCDANIEL, S. W.; BURNETT, J. J. Consumer religiosity and retail store evaluative criteria. Journal of the Academy of Marketing Science, v. 18, n. 2, p. 101-112, 1990.

MEAGHER, K. Trading on faith: religious movements and informal economic governance in Nigeria. The Journal of Modern African Studies, v. 47, n. 3, p. 397-423, 2009.

MICHELLON, E. O dinheiro e a natureza humana: como chegamos ao moneycentrismo? Rio de Janeiro: MK Editora, 2006.

MONDIN, B. Introduçáo à filosofia: problemas, sistemas, autores, obras. RENARD, J. (Trad.) MORALES, D. (Rev.). São Paulo: Ediçóes Paulinas, 1980.

MONTALVO, J. G.; REYNAL-QUEROL, M. Religious polarization and economic development. Economics Letters, v. 80, n. 2, p. 201-210, 2003.

NASCIMENTO, J. H. A.; ROCCO, L. de A. Economia da Religião: uma revisão de literatura. Encontros Universitários da UFV, v. 3, 2018.

NOLAND, M. Religion, Culture, and Economic Performance. Institute for International Economics Working, v. 3, n. 8, 2003.

NORTH, D. C. Institutions. Journal of Economic Perspectives, v. 5, n. 1, p. 97-112, 1991.

OLIVEIRA, L. L. S. de; CORTES, R. X.; BALBINOTTO NETO, G. A Economia da Religiáo e seus fundamentos: teste de um Modelo de Escolha Religiosa. Estudos Econômicos, v. 41, n. 4, p. 811-840, 2011. 
PACE, S. Effects of intrinsic and extrinsic religiosity on attitudes toward products: empirical evidence of value-expressive and social-adjustive functions. The Journal of Applied Business Research, v. 30, n. 4, p. 1227-1238, 2014.

PALDAM, M. Corruption and Religion Adding to the Economic Model. Kyklos, v. 54, n. 2\&3, p. 383-413, 2001.

PANAGARIYA, A.; MORE, V. Poverty by social, religious and economic groups in India and its largest states. Indian Growth and Development Review, v. 7, n. 2, p. 202-230, 2014.

PUTNAM, R. Making Democracy Work. Civic Traditions in Modern Italy. Princeton University Press, Princeton, 1993.

RENNEBOOG, L.; SPAENJERS, C. Religion, economic attitudes, and household finance. Oxford Economic Papers, v. 64, n. 1, p. 103-127, 2011.

SCHNEIDER, H.; KRIEGER, J.; BAYRAKTAR, A. The impact of intrinsic religiosity on consumers ethical beliefs: Does it depend on the type of religion? A comparison of christian and moslem consumers in Germany and Turkey. Journal of Business Ethics, v. 102, n. 2, p. 319-332, 2011.

SCHULTZ, T. W. Investment in Human Capital. The American Economic Review, v. 51, n. 1, p. $1-17,1961$.

SMITH, A. An Inquiry into the Nature and Causes of the Wealth of Nations. New York: Metalibri, 2007.

SOLT, F; HABEL, P.; GRANT, J. T. Economic Inequality, Relative Power, and Religiosity. Social Science Quarterly, v. 92, n. 2, p. 447-465, 2011.

SOLOW, R. M. (1956). A Contribution to the Theory of Economic Growth. Quarterly Journal of Economics, 70: 65-94.

STEUART, I. An investigation into the relationship between religion andeconomic development. Manuscript, 1998.

TAWNEY, R. H. Religion andthe Rise of Capitalism. Harper and Row, New York, 1926.

TERZIDOU, M.; STYLIDIS, D.; SZIVAS, E. M. Residents' Perceptions of Religious Tourism and its Socio-Economic Impacts on the Island of Tinos. Tourism and

Hospitality Planning \& Development, v. 5, n. 2, p. 113-129, 2008.

UELMEN, A. J.; BRUNI, L. Religious Values and Corporate Decision Making: The Economy of Communion Project. Fordham Journal of Corporate and Financial Law, 
Symposium on Religious Values and Corporate Decision Making, v. 11, p. 645-680, 2006.

UPPAL, J. S. Hinduism and economic development in South Asia. International Journal of Social Economics, v. 13, n. 3, p. 20-33, 1986.

VITELL, S.; PAOLILLO, J. G. P.; SINGH, J. J. Religiosity and consumer ethics. Journal of Business Ethics, v. 57, n. 2, p. 175-81, 2005.

WEAVER, G. R.; AGLE, B. R. Religiosity and ethical behavior in organizations: A symbolic interactionist perspective. Academy of Management Review, v. 27, n. 1, p. 77-97, 2002.

WEBER, M. A ética protestante e o espírito do capitalismo. São Paulo: Martin Claret, 1904.

WESSEL, I.; WINHOEFER, G. (Ed.) Violence in Indonesia. Hamburg: Abera Verlag Markus Voss, 2001.

WOODBERRY, R. D. Religion and the Spread of Human Capital and Political Institutions. In MCCLEARY, R. (Ed.). The Oxford Handbook of the Economics of Religion, New York: Oxford Univ. Press, 2011.

WUTHNOW, R. New directions in the study of religion and economic life. In: SMELSER, N. J.; SWEDBERG, R. (Eds). The handbook of economic sociology. 2nd ed. Princeton: Princeton University, p. 603-626, 2005.

YANG, F. Religion in China under Communism: A Shortage Economy Explanation. Journal of Church and State, v. 52, n. 1, p. 3-33, 2009.

YOUNG, C. Model Uncertainty in Sociological Research: An Application to Religion and Economic Growth. American Sociological Review, v. 74, n. 3, p. 380-397, 2009.

YUCHTMAN-YAAR, E.; ALKALAY, Y. Religious zones, economic development and modern value orientations: Individual versus contextual effects. Social Science Research, v. 36, n. 2, p. 789-807, 2007. 